\title{
Microstructural Modeling of the $\alpha+\beta$ Phase in Ti-6Al-4V: A Diffusion-Based Approach
}

\begin{abstract}
M. VILLA, J.W. BROOKS, R.P. TURNER, H. WANG, F. BOITOUT, and R.M. WARD
Complex heat treatment operations and advanced manufacturing processes such as laser or electronbeam welding will see the metallic workpiece experience a considerable range of temperatures and heating/cooling rates. These intrinsic conditions will have a significant bearing upon the microstructure of the material, and in turn upon the thermo-mechanical properties. In this work, a diffusion-based approach to model the growth and shrinkage of precipitates in the alpha + beta field of the common titanium alloy Ti-6Al-4V is established. Further, the numerical model is extended using a JMA-type approach to explore the dependency of the beta-transus temperature on extremely high heating rates, whereby dissolution alone is too slow to accurately describe the alpha to beta-phase transformation. Experimental heat treatments at rates of 5,50 , and $500{ }^{\circ} \mathrm{C} / \mathrm{s}$ were performed, and metallographic analysis of the samples was used to validate the numerical modeling framework predictions for lamellar shrinkage, while data from the literature has been used to evaluate the numerical modeling framework for the growth of equiaxed microstructures. The agreement between measurements and numerical predictions was found to be good.
\end{abstract}

https://doi.org/10.1007/s11663-019-01675-0

(C) The Author(s) 2019

\section{INTRODUCTION}

TITANIUM alloys are excellent material candidates for high-performance, extreme service-condition applications. Many aerospace structures including airframes, skin, and engine components have benefited from the use of titanium alloys, where the reduced weight and increased performance permit lower fuel consumption and emissions, factors which are becoming increasingly important. ${ }^{[1]}$ An important factor within any component manufacturing process is the joining method to be used for the alloy of interest. Although there are numerous different joining methods of potential use, welding can produce components that are lighter, have greater structural integrity, and are cheaper than other methods can achieve (e.g., riveting) ${ }^{[2]}$ However, in order to produce a welded joint with the required structural integrity and material properties, one must consider the metallurgical, thermal, and mechanical fields to optimize the outputted joint.

M. VILLA, J.W. BROOKS, R.P. TURNER and R.M. WARD are with the School of Metallurgy \& Materials, University of Birmingham, Birmingham, B15 2TT, United Kingdom. Contact e-mails: r.p.turner@bham.ac.uk; r.m.ward@bham.ac.uk. H. WANG is with the School of Metallurgy \& Materials, University of Birmingham and also with the College of Materials, Metallurgy and Chemistry, Jiangxi University of Science and Technology, Ganzhou, Jiangxi, 341000, P.R. China. F. BOITOUT is with the ESI Group, Lyon 69006, France.

Manuscript submitted April 5, 2019.

Article published online September 4, 2019.
Numerical methods have been developed to describe the thermal, metallurgical, and mechanical phenomena associated with welding; however, the behavior of many materials are so complex that simple analytical solutions are typically insufficient to predict material behavior during a welding process with sufficient accuracy. ${ }^{[2]}$ In particular, mechanical properties of materials are strongly dependent upon the microstructure present, and the rate at which microstructure changes in response to local thermal fields are often complex. A requirement for greater accuracy is being met by numerical methods where the governing thermal, mechanical, and metallurgical equations can be solved over a series of fine volumetric regions, which has led to the potential for location-specific behavioral solutions. The traditional finite element numerical methods are an example of this, and their increasing use gives researchers the chance to further their understanding of these complex interactions during welding and other processes.

Sysweld (ESI Group) is a specialist welding FE code, which contains a microstructural modeling framework based on sub-routines originally developed for steels, ${ }^{[3-5]}$ where the temporally evolving phase proportion is described by phenomenological equations. However, to accurately predict the mechanical behavior for a titanium alloy such as Ti-6Al-4V, as well as the distribution of phases it is also necessary to predict the morphology of the grains developed during the process, and in particular the dimensions of spherical, lamellar, and acicular grains, ${ }^{[6-8]}$ to allow for accurate mechanical property predictions. 
An improved FE method for predicting metallurgical and mechanical behavior of Ti-6Al-4V when subjected to a high energy density welding process is therefore of considerable interest to the modeling community. A diffusion-based approach is presented to describe alphaphase evolution in the $\alpha+\beta$ field, for the equiaxed and lamellar morphologies. This model is integrated with a JMA equation to describe the change of crystallographic structure for conditions close to the beta-transus temperature and with fast heating rates. Both experimental and literature data are used to validate the numerical predictions. An overarching requirement of the metallurgical modeling framework is to generate models capable of being implemented in commercial simulation software and being calculated on a workstation computer without significantly increasing the computational time.

\section{MATERIAL AND METHODS}

The cylindrical samples used for the experimental investigation were taken from 16-mm-thick Ti-6Al-4V plate, with a measured chemical composition given in Table I. Samples were machined to a length of $110 \mathrm{~mm}$ and diameter of $6 \mathrm{~mm}$. Further specimens of size $10 \mathrm{~mm} \times 10 \mathrm{~mm} \times 2 \mathrm{~mm}$ were machined from the plate to determine the beta-transus temperature. A glass coating was applied over each sample before the heat treatments as protection against oxidation. The microstructure of the as-received material is shown in Figure 1. All the microstructure images presented were determined via backscattered electron imaging (BEI) using a scanning electron microscope. In these images, the alpha phase appears with a darker color as its atomic number is lower than the beta phase, which appears brighter. The beta-transus temperature was determined by soaking samples in a furnace for 20 minutes at temperatures of $960{ }^{\circ} \mathrm{C}, 970{ }^{\circ} \mathrm{C}$, and $980{ }^{\circ} \mathrm{C}$. The parent alpha phase was then measured and, when it was completely transformed, the beta-transus temperature was assumed to have been passed.

To study the dissolution of the microstructure during heat treatments, the 6-mm-diameter samples were subjected to different isochronal heat ramps using the digital closed loop control thermal and mechanical testing system Gleeble 3500, (Dynamic Systems Inc). To allow the Gleeble machine to control the temperature at which the samples were subjected during the tests, three type-B thermocouples were spot welded on to the specimens, at the mid-length location and at 4 and 8 $\mathrm{mm}$ from the mid-length, respectively. The Gleeble system produces a parabolic temperature distribution across the sample, so three different heat treatment results could be obtained from each specimen.
In the literature, a common procedure adopted for lamellae thickness measurement consists of collecting a series of intercept readings by rotating a grid of parallel lines at many angular steps, till a complete rotation of 360 deg has occurred. ${ }^{[9]}$ The mean length of all intersections of the regular grid, for each lamellae, multiplied by a factor 1.5 and inverted, would return the hypothetical true mean value of the lamellae measured. However, this approach would have only allowed for lamellae thickness measurements.

Thus, to estimate the evolution of the lamellae in twodimensions, their width and length in the as-received microstructure have been characterized. Ellipses were manually inscribed with the major axis coincident with the length of the lamellae, and the minor axis coincident with the thickest section of the lamellae considered (Figure 1). The mean lamellae thickness was calculated, and by the ratio of the mean length and mean thickness, the mean aspect ratio was estimated. In this work, only lamellae colonies appearing with sharper boundaries were considered. This reduced the effect of the random inclination of the sectioning plane used. Colonies not sectioned perpendicularly to their longitudinal direction would appear with darker areas close to their boundaries (shadow effects) and, usually, it could be noticed that these lamellae had overall larger interior and boundary thicknesses. The volume fractions of alpha and beta phase were estimated by thresholding image analysis. Detailed image analysis was performed to further understand the microstructural evolution present within samples.

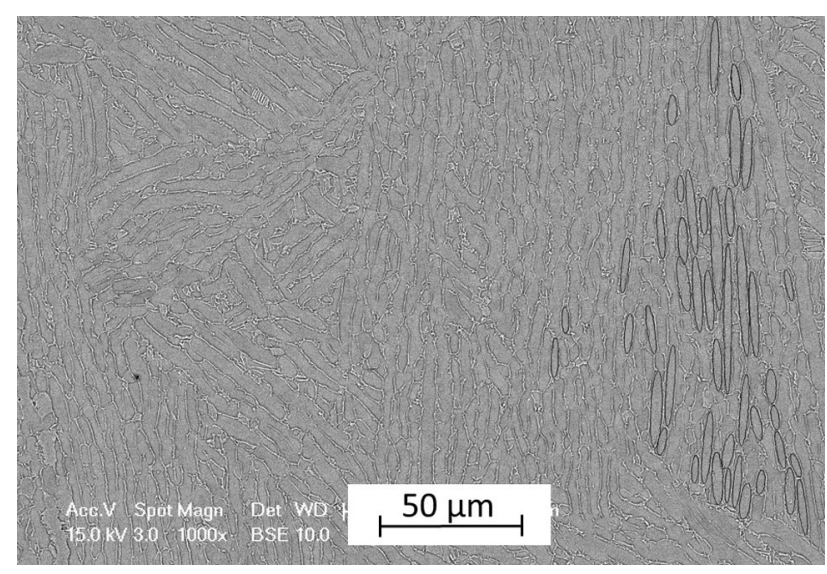

Fig. 1-The as-received Ti-6Al-4V microstructure. Ellipses have inscribed on the right of the image, to characterize the lamellae dimensions.

Table I. Measured Composition of the Ti-6Al-4V Nominal Plate

\begin{tabular}{lccccrrr}
\hline Element & Al & V & Fe & H & N & O & Ti \\
\hline Weight Percent & 5.75 & 3.96 & 0.07 & 0.00445 & 0.013 & 0.11 & bal. \\
\hline
\end{tabular}




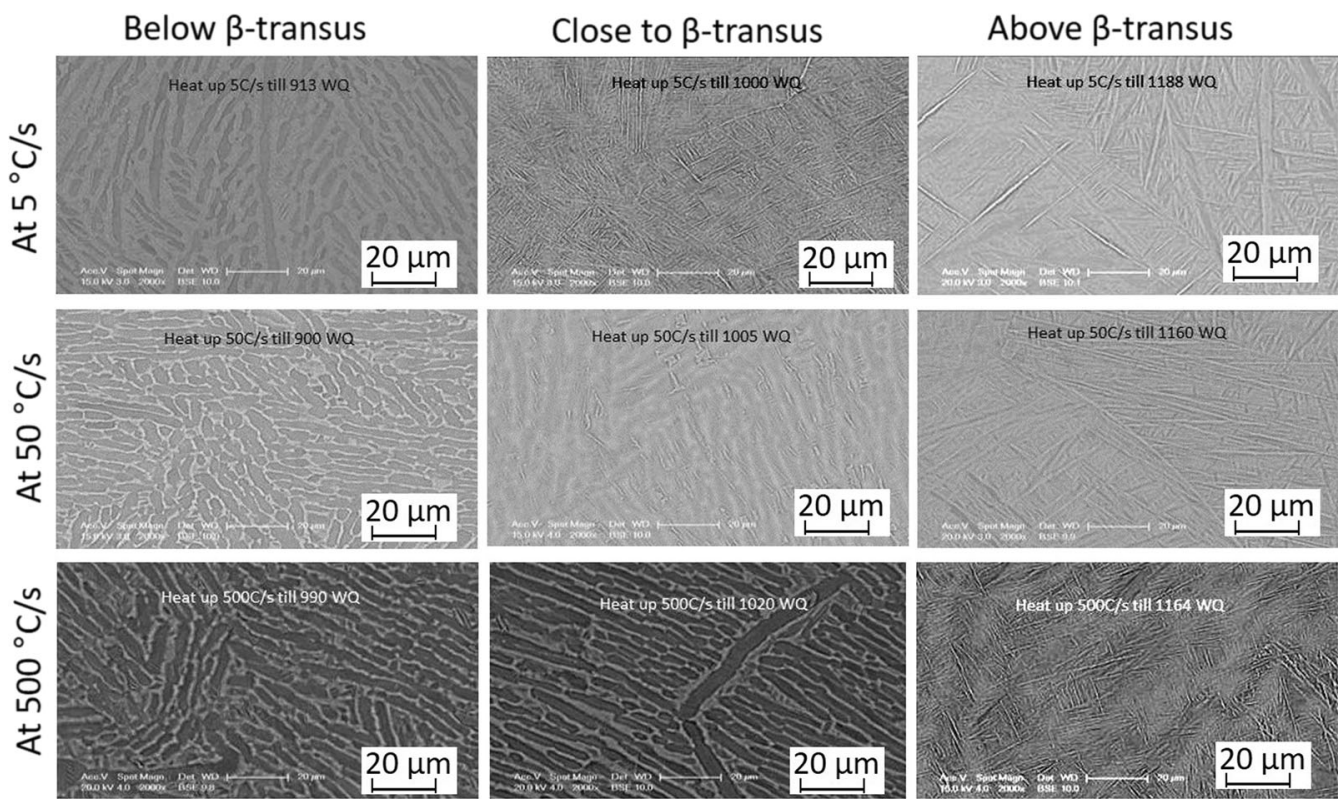

Fig. 2-Microstructure obtained at temperatures below, close to and exceeding the beta-transus temperature, considering heating rates of 5, 50, and $500{ }^{\circ} \mathrm{C} / \mathrm{s}$.

\section{RESULTS}

\section{A. Microstructure Observations}

The parent alpha lamellar microstructure during heating dissolves into the beta phase. As the material is subsequently cooled by water quenching (with rates in excess of $300{ }^{\circ} \mathrm{C} / \mathrm{s}$ ), a martensitic microstructure develops in place of the beta phase, if peak temperature and cooling rate are both sufficient. The as-received material has a mean lamellae thickness of approximatively $3.0 \mu \mathrm{m}$ with a standard deviation of $0.5 \mu \mathrm{m}$. The samples were tested at heating rates of 5,50 , and $500{ }^{\circ} \mathrm{C} / \mathrm{s}$.

Representative microstructures, taken from each tested sample, are reported in Figure 2 for heating rates of 5,50 , and $500{ }^{\circ} \mathrm{C} / \mathrm{s}$. Dissolution of the darker alphaphase lamellae and growth of the brighter beta phase can be observed as temperatures increase and heating rate gets higher. When the lamellae are no longer recognizable and martensitic needle-like structures appear, the material passed the beta-transus temperature, and cooled sufficiently quickly. Through analyzing the SEM images, one can deduce that the beta-transus temperature was below $976{ }^{\circ} \mathrm{C}$ for a heating rate of $5{ }^{\circ} \mathrm{C} / \mathrm{s}$, between $966{ }^{\circ} \mathrm{C}$ and $982{ }^{\circ} \mathrm{C}$ for a heating rate of $50{ }^{\circ} \mathrm{C} / \mathrm{s}$, and exceeds $1020{ }^{\circ} \mathrm{C}$ for a heating rate of $500^{\circ} \mathrm{C} / \mathrm{s}$.

The kinetics of the diffusion process require a dwell time to allow the metallurgical transformation to occur. In a sufficiently fast heating process, there is insufficient time above the beta-transus for complete dissolution of the lamellae before quenching: their thickness at temperatures close to the beta-transus can remain quite large and the solid-state crystallographic change from HCP to BCC occurs before their complete dissolution. ${ }^{[10]}$ Additionally, concentrations of the constituent elements within different phases do not have time to change to the equilibrium concentration. This is particularly visible when the peak temperature only just exceeded the beta-transus temperature, and the brighter (beta) and darker (alpha) fields associated with the asreceived microstructure in the lamellar morphology can be still observed.

Figure 3 compares the results of the alpha lamellae and beta-phase thickness measurements from the image analysis. As the heating rate increases, the alpha lamellae dissolution and beta-phase growth tend to shift toward higher temperatures and alpha volume fraction. This is due to the limited speed of the diffusion kinetics. The thickness of the beta phase is indicative of the impact that heating rate has upon the duplex microstructure of the $\alpha / \beta$ titanium alloy. However, Figure 4 illustrates the measured alpha-phase lamellar volume fraction during heating and the aspect ratio of the lamellae, for the three different considered heating rates, again taken from image analysis.

\section{MATHEMATICAL MODELLING FRAME- WORK}

\section{A. Field and Flux Balance}

The kinetics of the growth and shrinkage of equiaxed and lamellar alpha in the $\alpha+\beta$ field are modeled using a single element diffusion analysis of an isolated particle in an infinite matrix, ${ }^{[11]}$ but adapted to a finite matrix case where the system overall solute concentration is constant. ${ }^{[12]}$ The assumption that the diffusion process is driven mainly by a single diffusing element is a simplification that for both Ti-6Al-4V and other alloys has been successfully used in the literature. ${ }^{[9,14,15]}$ For an infinitesimal time step, the two equations describing the solute flux in a particle are ${ }^{[11,13]}$ the field equation (Eq. [1]) and the flux balance (Eq. [2]): 


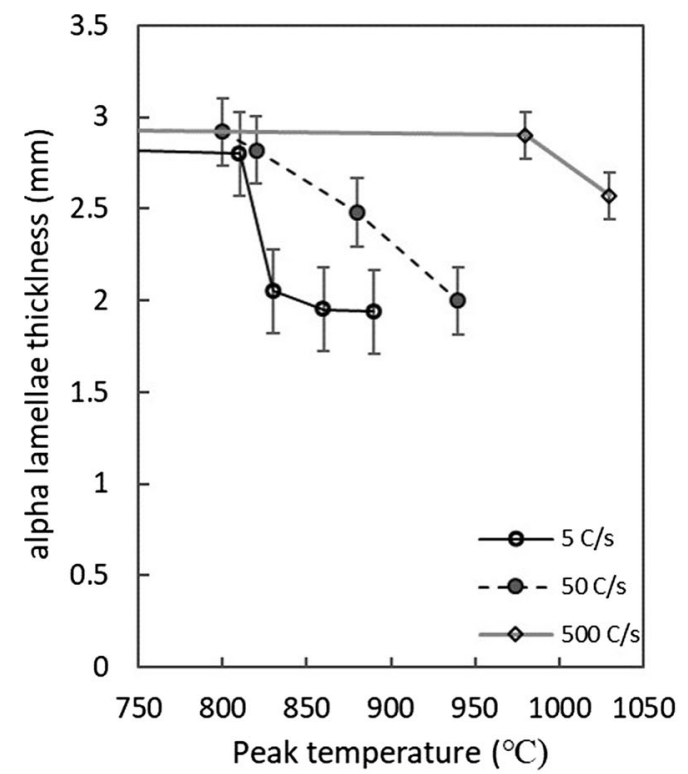

(a)

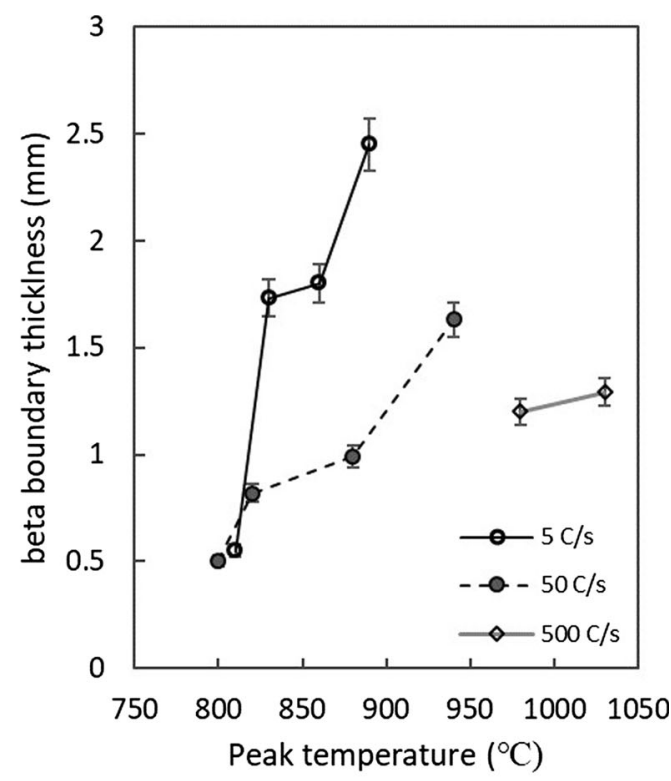

(b)

Fig. 3-Heating rate effect on $(a)$ the dissolution of alpha lamellae, and $(b)$ growth of beta boundaries for different heating rates, as a function of the heating rate and peak temperature.

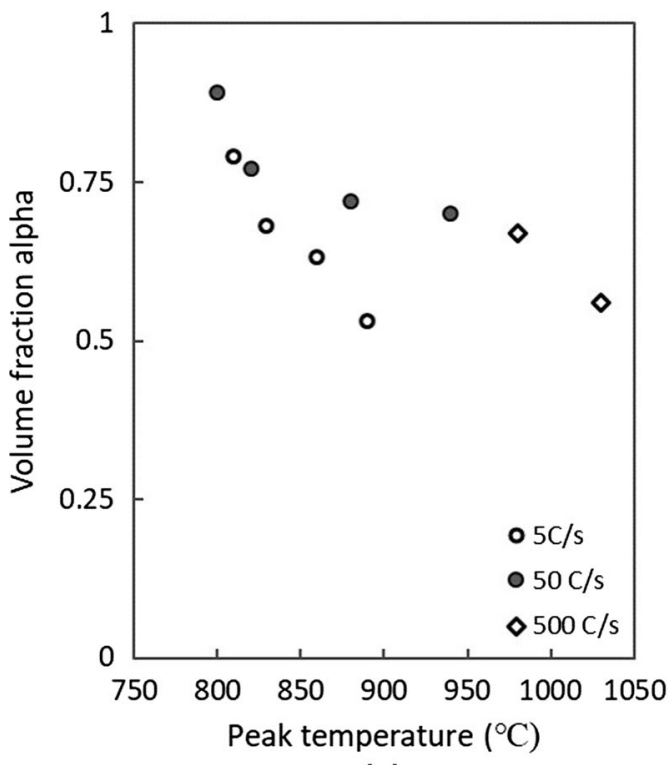

(a)

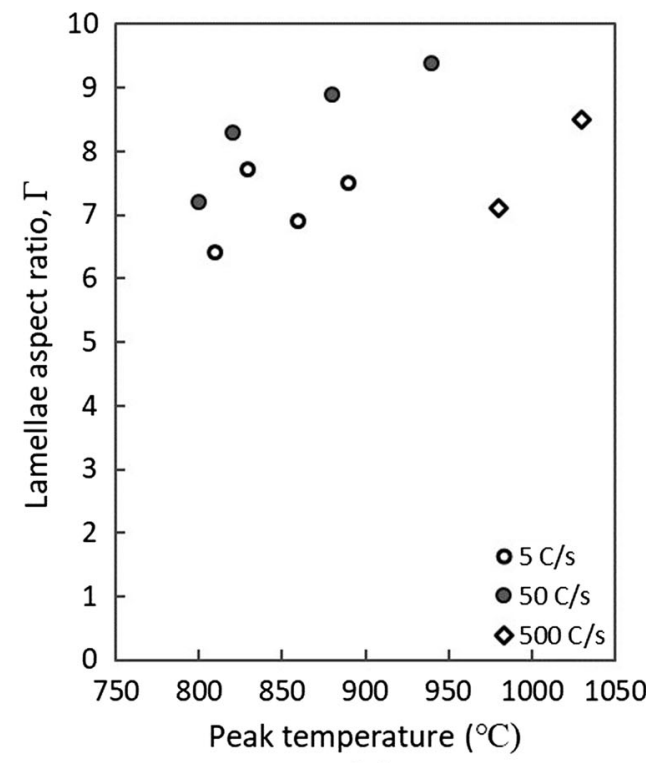

(b)

Fig. 4-Variation of $(a)$ volume fraction of alpha lamellae, and $(b)$ alpha lamellae aspect ratio as a function of peak temperature and heating rate.

$$
\begin{gathered}
D \nabla^{2} C=\frac{\partial C}{\partial t} \\
\left(C_{p}-C_{I}\right) \frac{d R}{d t}=\left.D \frac{\partial C}{\partial t}\right|_{r=R}
\end{gathered}
$$

where $D$ represents the inter-diffusion coefficient considered independent of composition for the time $d t, C$ the solute concentration, $t$ the time, $R$ the radius of the particle, $C_{p}$ the solute concentration in the matrix-particle interface at the particle side, and $C_{I}$ the solute concentration in the matrix-particle interface at the matrix side.

Where possible, the exact solutions of the field equation (Eq. [1]) and flux balance (Eq. [2]) have been used; otherwise, simplified conditions have been applied. The concentration field in the matrix is assumed, during growth, to deplete the matrix immediately ahead of its interface ${ }^{[16,17]}$ since a solute is needed to increase the particle dimensions. Conversely, during shrinkage, the 
precipitate rejects solute that moves toward the matrix, resulting in a gradual decrease in the solute distribution from the particle to the matrix. ${ }^{[1]}$

Assuming incoherent diffusion controlled growth, at the interface a local equilibrium can be assumed ${ }^{[18]}$ and $C_{\mathrm{I}}$ is then considered to be the equilibrium concentration of the matrix phase. $C_{P}$ is considered constant and equal to the value at the beginning of the heat treatment. This implies that (i) the diffusion coefficient in the precipitate is small compared to the one in the matrix, and/or (ii) the solute concentration in the precipitate is independent from the distance from the particle-matrix interface and temperature. ${ }^{[17]}$ Hypothesis (i) cannot be fully verified by literature data as the diffusivity of vanadium in the alpha phase was not found. But it can be considered reasonable if the order of magnitude of the vanadium diffusivity in alpha titanium is assumed to be similar to that for aluminum reported. ${ }^{[19]}$ Semiatin et al. ${ }^{[14]}$ reported that the diffusivity in the beta phase of aluminum is similar to that of vanadium (Eqs. [1] and [2]). Accepting this hypothesis, an approximate comparison of concentration gradient-driven diffusion in the alpha and beta phases can be made. In the alpha phase the diffusion rate, driven by concentration gradients, ranges from $10^{-9} \mu \mathrm{m}^{2} / \mathrm{s}$ at $950 \mathrm{~K}$ to $10^{-5} \mu \mathrm{m}^{2} / \mathrm{s}$ at $1150 \mathrm{~K}$, and for the same range of temperatures in the beta phase the diffusivity increases from $6 \times 10^{-4}\left(\mu \mathrm{m}^{2} / \mathrm{s}\right)$ to $2.5 \times 10^{-2}\left(\mu \mathrm{m}^{2} / \mathrm{s}\right)$. The diffusivity in the beta phase is estimated to be up to 1000 times faster. Thus assuming that these hypotheses are valid, the following boundary conditions can be applied for the solution of the field and heat flux equations where $C_{M}$ is the solute concentration in the matrix, and are shown graphically in Figure 5.

$$
\begin{array}{cc}
C(r=R, t)=C_{I} & 0<t \leq \infty \\
C(r, t=0)=C_{M} & r \geq R \\
C(r=\infty, t)=C_{M} & 0 \leq t \leq \infty
\end{array}
$$

\section{B. Spherical Particles}

\section{Growth}

The exact solution of the field and flux balance equations, when applying the boundary conditions in Eq. [3], and using radial coordinates, expresses the concentration field and the radius variation in time as $^{[11,14]}$

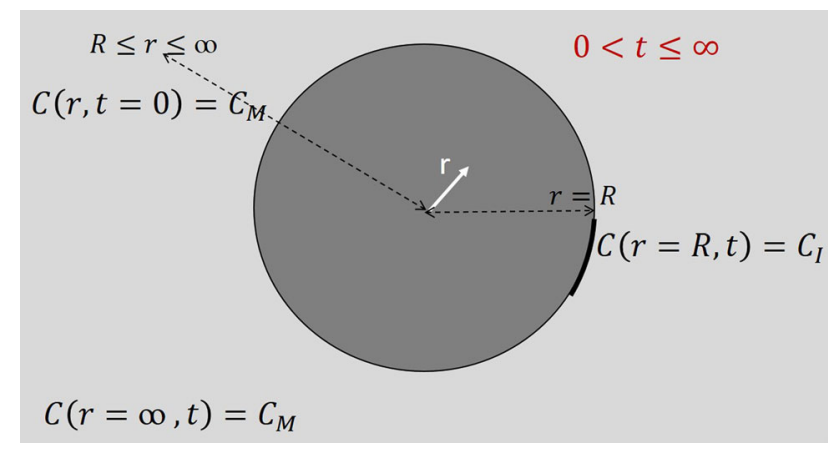

Fig. 5-Boundary conditions applied to the solution of the heat flux and concentration field equation.

$$
\begin{aligned}
& C(r, t)-C_{M} \\
& \quad=\frac{2 \lambda\left(C_{I}-C_{M}\right)}{e^{-\lambda^{2}}-\lambda \pi^{\frac{1}{2}} \operatorname{erfc}(\lambda)}\left[\frac{(D t)^{\frac{1}{2}}}{r} e^{-\left(\frac{r^{2}}{4 D t}\right)}-\frac{1}{2} \pi^{\frac{1}{2}} \operatorname{erfc}\left(\frac{r}{2(D t)^{\frac{1}{2}}}\right)\right]
\end{aligned}
$$

$$
\frac{d R}{d t}=2 \lambda^{2} \frac{D}{r}
$$

where $\lambda$ is a function of the supersaturation $\Omega$ :

$$
\begin{gathered}
\lambda^{2} e^{\lambda^{2}}\left[e^{-\lambda^{2}}-\left(\lambda \pi^{\frac{1}{2}} \operatorname{erfc}(\lambda)\right)\right]=\frac{\Omega}{2} \\
\operatorname{erfc}(\lambda)=\frac{2}{\sqrt{\pi}} \int_{\lambda}^{\infty} e^{-t^{2}} d t \\
\Omega=\frac{C_{M}-C_{I}}{C_{P}-C_{I}}
\end{gathered}
$$

The solute concentration in the matrix $C_{M}$ is computed taking into consideration the soft impingement on the far-field composition, using a mass balance, where the overall solute concentration of the alloy $\left(C_{0}\right)$ is given by the sum of the solute concentration in the alpha phase $\left(C_{\alpha}\right)$ and in the matrix $\left(C_{M}\right)$ :

$$
C_{0}=f_{\alpha} C_{\alpha}+\left(1-f_{\alpha}\right) C_{M}
$$

And $C_{M}$ can thus be obtained from Eq. [9] by simple re-arrangement:

$$
C_{M}=\frac{C_{0}-f_{\alpha} C_{\alpha}}{1-f_{\alpha}}
$$

In Eq. [10], the precipitate composition $\left(C_{\alpha}\right)$ is considered equal to $C_{P}$, in agreement with the initial hypothesis, and the phase fraction of the precipitate $f_{\alpha}$ is considered proportional to its initial value $\left(f_{\alpha 0}\right)$ multiplied by the cube of the ratio between the current radius of the particle and its original dimension $\left(R_{0}\right),{ }^{[9]}$ which yields Eq. [11] (assuming a constant number of nuclei during the process, and requires the initial volume fraction to be determined):

$$
f_{\alpha}=f_{\alpha 0}\left(\frac{R}{R_{0}}\right)^{3}
$$

The assumptions involved for the calculation of $C_{M}$ in Eq. [10] neglect the precise solute concentration in the region adjacent to the precipitate. This simplification introduces a small 0.5 to 1.5 pct under-prediction of the volume fraction of primary alpha transformed. ${ }^{[9]}$ Phase field calculations ${ }^{[20]}$ support this hypothesis, in particular for long annealing times.

The inter-diffusion coefficient D was determined as a function of the composition and temperature at each delta time dt, using Darken's equation (Eq. [12]) for a binary system ${ }^{[18]}$. 


$$
D=F\left(X_{B} D_{A}^{*}+X_{A} D_{B}^{*}\right)
$$

This assumption has been made considering the diffusion process to be driven by only one element such as aluminum or vanadium diffusing in a titanium matrix, in an analogous way to the growth model. Recent work in the literature has adopted this procedure, and has obtained good predictions compared with experimental results. ${ }^{[9,12,14]}$ In equation $12, D_{A}^{*}$ and $D_{B}^{*}$ are the intrinsic diffusion coefficients of the binary system of $A$ and $B$ elements, where in case of the current work $A$ can be represented by vanadium or aluminum and $B$ is titanium. The term $F$ in Eq. [12] is the thermodynamic factor, expressed as

$$
F=\frac{X_{A} X_{B}}{R T} \frac{d^{2} G}{d X^{2}}
$$

where $X_{i}$ represents the molar fraction of the element $A$ or $B$ (as in Equation 12), $R$ is the gas constant, $T$ the temperature in Kelvin, and $\frac{d^{2} G}{d X^{2}}$ the second derivative of the Gibbs free energy with respect to the mole fraction of the element $X$.

\section{Shrinkage}

As discussed in the literature, ${ }^{[1]}$ the exact solution of the field and flux balance equations for a dissolving sphere is not possible, and thus a stationary interface $\left(\frac{\partial R}{\partial t}=0\right)$ is assumed. ${ }^{[1,21]}$ As observed in, ${ }^{[17]}$ the stationary interface approximation can describe the kinetics satisfactorily when the supersaturation is within 0.3 such that the growth rate is not particularly high. Equations [14] and [15] describe, respectively, the concentration field around the particle and its shrinkage rate.

$$
\begin{gathered}
C(r, t)=\left\{\left[\left(C_{I}-C_{M}\right) R\right] / r\right\} \operatorname{erfc}\left[(r-R) / 2(D t)^{\frac{1}{2}}\right] \\
\frac{d R}{d t}=\frac{\Omega D}{4 R}+\frac{\Omega}{4} \sqrt{\frac{D}{\pi t}}
\end{gathered}
$$

All the terms have been already explained previously. The complementary error function $(e r f c)$ has the form as given in Eq. [7].

\section{Lamellar $\alpha$-Phase Particles}

\section{Growth}

The lamellar particle growth has been modeled using the solution proposed in References 13, 22, and 23 for an ellipsoidal shape, whose aspect ratio between minor and major axis remains constant. In Reference 9, it has been stated that this solution gives better results than a semi-infinite plate solution, where the growth of the particle seems to be underestimated. However, this approach does not consider the initial stage of the growth of lamellar particles, where after nucleation a lengthening phase follows ${ }^{[23]}$ until lamellae mechanically impinge on each other. Since nucleation is out of scope for this model, the assumption of a constant aspect ratio is assumed to be reasonable for the description of growth and shrinkage in the $\alpha+\beta$ field. Nucleation and lengthening combined could be considered using a further analytical model. ${ }^{[24]}$

Experiment showed that the aspect ratio has relatively little change as the lamellae thinning occurs (Figure 4(b)). Consequently, a sensitivity analysis of the numerical model to this variation was conducted, confirming that the changes involved have negligible effect on the final predictions (Figure 6).

The ellipsoidal approach describes the half length of the major $(Y)$ and minor axis $(X)$ of the $3 \mathrm{D}$ prolate spheroid representing the lamellar particle by, respectively, Eqs. [16] and [17]:

$$
Y=2 \Gamma(\delta D t)^{\frac{1}{2}}
$$

$$
X=2(\delta D t)^{\frac{1}{2}}
$$

where $\Gamma$ is the aspect ratio given by $\mathrm{Y} / \mathrm{X}$, and $\mathrm{D}$ the inter-diffusion coefficient as in Eq. [1]. The dimensionless growth parameter $\delta$ is determined with Eq. [18], where $\Omega$ is the supersaturation (Eq. [8]).

$$
\Omega=e^{\delta}\left(\delta^{\frac{3}{2}} \Gamma^{2}\right) \int_{u=\delta}^{u=\infty} \frac{e^{-u} d u}{\left\{\delta\left(\Gamma^{2}-1\right)+u\right\} u^{\frac{1}{2}}}
$$

The solution of Eq. [18] has been computed using the commercial software package Matlab and its behavior is shown in Figure 7. The volume of the ellipsoid, considering Eqs. [16] and [17], is then determined by Eq. [19].

$$
\frac{d V_{e}}{d t}=8 \pi \Gamma^{2} \delta D X
$$

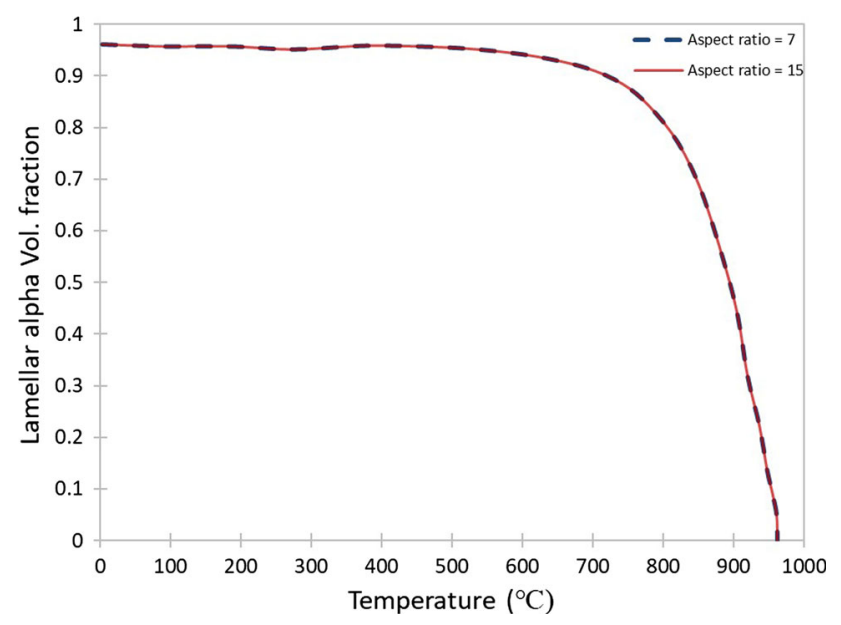

Fig. 6-Negligible sensitivity of the predicted evolution of the alpha lamellae volume fraction to lamellae aspect ratio. 


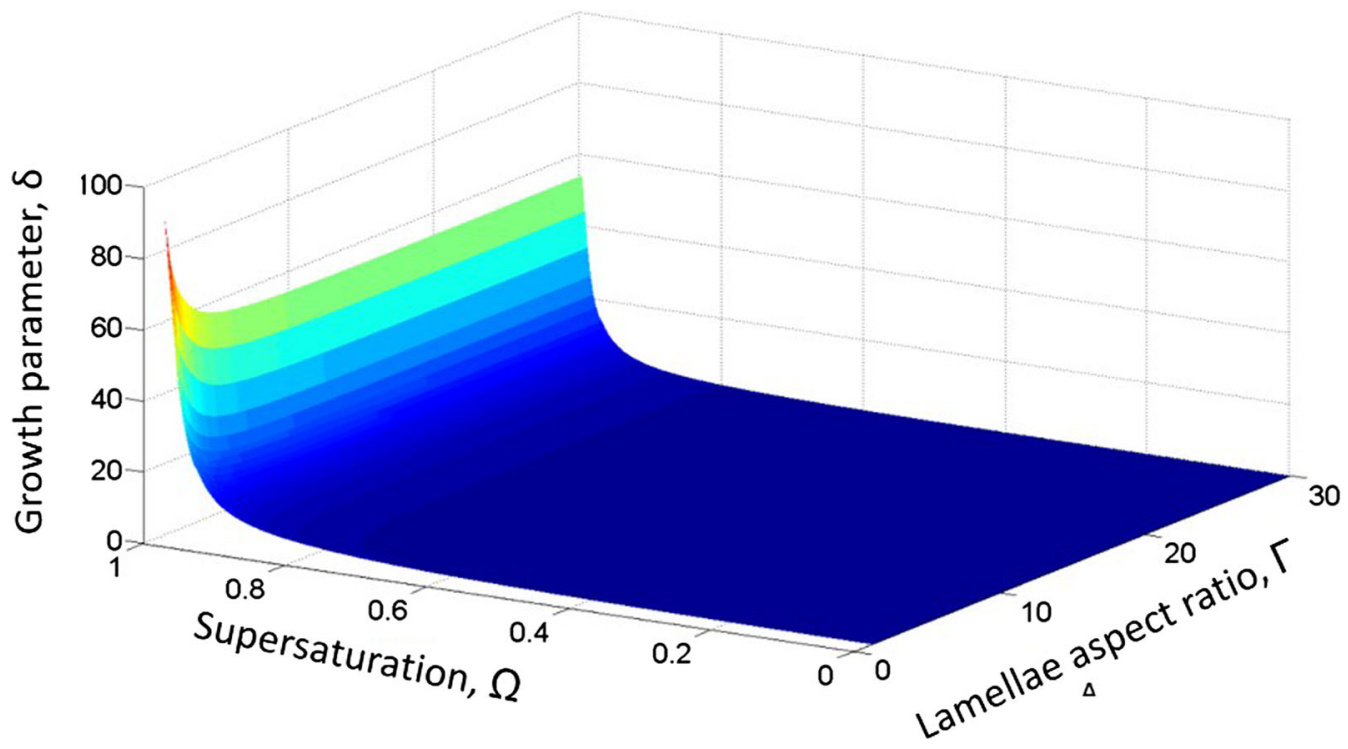

Fig. 7-Solution of the Eq. [18], showing dependence of Delta $(\delta)$ as a function of $\Omega$ and aspect ratio $(\Gamma)$.

\section{Shrinkage}

To model the thinning of lamellar particles, the calculations have been based on diffusional shrinkage of a semi-infinite plane. The exact solution of the field and flux balance equations for a dissolving sphere is not possible, and thus a stationary interface $\left(\frac{\partial R}{\partial t}=0\right)$ is assumed. ${ }^{[1]}$ The exact solution of the concentration field is represented in Eq. [20], while the thickness of the plate is described by Eq. [21], with parameters $\lambda_{1}$ and $\alpha$ described in Eqs. [22] and [23].

$$
\begin{gathered}
C(x, t)-C_{M}=\left(C_{I}-C_{M}\right) \frac{\operatorname{erfc}\left[\left(x-S_{0}\right) / 2(D t)^{\frac{1}{2}}\right]}{\operatorname{erfc}(-\lambda)} \\
S=S_{0}-\lambda_{1}(D t)^{\frac{1}{2}} \\
\lambda_{1}=\lambda / 2 \\
\pi^{\frac{1}{2}} \lambda e^{\lambda^{2}} \operatorname{erfc}(-\lambda)=\Omega / 2
\end{gathered}
$$

\section{Diffusion}

The intrinsic diffusion coefficients have been expressed as Arrhenius equations ${ }^{[14]}$ where $\beta$ is the diffusivity of the elements considered to be in the beta titanium matrix.

$$
\begin{gathered}
D_{\mathrm{V}}^{\beta}\left(\frac{\mu m^{2}}{s}\right)=10^{5} e^{\left(-\frac{17460}{T(K)}\right)} \\
D_{\mathrm{Ti}}^{\beta}\left(\frac{\mu m^{2}}{s}\right)=2 \times 10^{4} e^{\left(-\frac{15000}{T(K)}\right)} \\
D_{\mathrm{Al}}^{\beta}\left(\frac{\mu m^{2}}{s}\right)=1.2 \times e^{\left(-\frac{18040}{T(K)}\right)}
\end{gathered}
$$

For the calculation of $\frac{d^{2} G}{d X^{2}}$, the Gibbs free energy formulation in a beta matrix for a Ti-Al-V ternary system has been used (Eq. [27]). ${ }^{[25]}$ The Gibbs free energy total contribution is represented by the sum of the Gibbs free energy of a mechanical mixture of the constituents of the phase (Eq. [28]), the entropy of mixing for an ideal solution (Eq. [29]), and the excess term (Eq. [30] ${ }^{[26]}$ : 


$$
\begin{gathered}
G^{\beta}=G^{0}+G^{\text {ideal }}+G^{\mathrm{xs}} \\
G^{0}=X_{\mathrm{Al}} G 0_{\mathrm{Al}}^{\mathrm{BCC}}+X_{\mathrm{Ti}} G 0_{\mathrm{Ti}}^{\mathrm{BCC}}+X_{V} G 0_{\mathrm{V}}^{\mathrm{BCC}} \\
G^{\text {ideal }}=\Upsilon T\left(X_{\mathrm{Al}} \ln X_{\mathrm{Al}}+X_{\mathrm{Ti}} \ln X_{\mathrm{Ti}}+X_{\mathrm{V}} \ln X_{\mathrm{V}}\right) \\
G^{\mathrm{xs}}=X_{\mathrm{Al}} X_{\mathrm{Ti}}(-125485+36.8394 T) \\
+X_{\mathrm{Al}} X_{\mathrm{V}}\left[(-95000+20 T)+(-6000)\left(X_{\mathrm{Al}}-X_{\mathrm{V}}\right)\right] \\
+X_{\mathrm{Ti}} X_{\mathrm{V}}\left[(10500-1.5 T)+2000\left(X_{\mathrm{Ti}}-X_{\mathrm{V}}\right)\right. \\
\left.+1000\left(X_{\mathrm{Ti}}-X_{\mathrm{V}}\right)^{2}\right]+X_{\mathrm{Al}} X_{\mathrm{Ti}} X_{\mathrm{V}}\left[X_{\mathrm{Al}}(116976.3\right. \\
-9.067 T)+X_{\mathrm{Ti}}(-175169+59 T)+X_{\mathrm{V}}(31107.3 \\
-42.316 T)]
\end{gathered}
$$

where $X_{x}$ is the mole fraction of the element $x$ at the temperature considered, $G 0^{\mathrm{BCC}}$ is the Gibbs free energy of the pure element $x,^{\left[2^{2}\right]}$ and $\mathrm{T}$ is the temperature in Kelvin. The effect of trace elements, beyond $\mathrm{Ti}, \mathrm{Al}, \mathrm{V}$ on the Gibbs free energy, such as $\mathrm{O}, \mathrm{Fe}, \mathrm{C}$, has not been considered. This simplification was considered sufficiently precise as the errors in the prediction of the actual Gibbs free energy were found to be within 2 pct. These were compensated by a simplification of the model and shorter running times when compared with the use of an interface with Thermocalc ${ }^{\circledR}$ to get the actual Gibbs free energy values.

All the considerations for the calculation of the interdiffusion coefficient $D$ were considered valid for all the models presented in this work. The intrinsic diffusion coefficients reported in Eqs. [24] through [26] were corrected by the thermodynamic factor (Eq. [13]). The resulting inter-diffusion coefficient is dependent on the temperature and concentration of the beta matrix at the precipitate/matrix interface.

\section{MODEL VALIDATION}

\section{A. Spherical Precipitate Growth}

To validate the model, data in the literature ${ }^{[9,11-14]}$ on the study of the spherical particle growth have been used. Thus, the microstructural measurements prior to heat treatment from the relevant literature sources were used as the initial conditions for the numerical model: initial average radius of the spherical particles $4.5 \mu \mathrm{m}$, initial phase fraction of spherical particles 0.27 , material composition (in weight percent) of 6.4 aluminum, 4.2 vanadium, 0.14 iron, 0.19 oxygen, 0.016 carbon, 0.004 hydrogen, 0.005 nitrogen, and the balance titanium. The alpha-phase fraction of 0.27 was obtained by soaking the material at $955^{\circ} \mathrm{C}$ for 1 hour and then water quenching it. The heat treatments tested consisted of cooling at 3 different cooling rates $\left(11,42\right.$, and $194^{\circ} \mathrm{C} /$ min) starting from a soaking temperature of $955^{\circ} \mathrm{C}$ after a 20 -minute hold.

The $C_{P}$ value in Eq. [8] has been set as the equilibrium concentration of the diffusing element in the alpha phase, at the starting temperature of the heat treatment, and it was kept constant during the heat treatment. This assumption gives negative values of the supersaturation for the first stage of the heat treatments because the initial alpha-phase fraction (0.27) is higher than the equilibrium value for $955^{\circ} \mathrm{C}$ and, consequently, the particle tends initially to reduce its dimension.

The initial soaking prior to heat treatment $\mathrm{t}^{[14]}$ is not enough to obtain the equilibrium microstructure at $955^{\circ} \mathrm{C}$. A composition of the particle $\left(C_{P}\right)$ corresponding to the equilibrium value at about $900{ }^{\circ} \mathrm{C}$ would not give the initial shrinkage but, since Reference 14 does not report the actual initial value of $\mathrm{C}_{\mathrm{P}}$, the original solution presented has been preferred. A comparison with a hypothetical model where negative supersaturation values give no shrinkage has been made. In this manner, the impact of the different particle dimensions and relative solute concentrations has been evaluated on the final phase fraction predicted.

The effects of different cooling rates $\left(11,42,194{ }^{\circ} \mathrm{C} /\right.$ min) on the kinetics of growth have been investigated (Figure 8) starting from a peak temperature of $955^{\circ} \mathrm{C}$ and considering either vanadium or aluminum as the diffusing element. The numerical model, when compared with experimental results, describes the phase fraction evolution well, in particular for vanadium. Literature ${ }^{[28]}$ does suggest that vanadium is the limiting element in diffusion-driven processes in Ti-6Al-4V.

The effect of the initial particle size $( \pm 0.5 \mu \mathrm{m})$ on the alpha-phase proportion is considered (Figure 9), for the $11^{\circ} \mathrm{C} / \mathrm{min}$ cooling rate with vanadium as the diffusing element. Such small variations in the particle size are plausible both for microstructural variations within the material $^{[29]}$ and measurement uncertainty, but their impact on the growth kinetics seems modest: a variation of \pm 12 pct on the diameter of the particle returns a variation on the alpha-phase growth of \pm 3 pct. An interesting observation is the smaller growth rate shown when aluminum is considered to be the diffusing element instead of vanadium, even though its inter-diffusion coefficient is higher. This is due to the smaller supersaturation related to aluminum, since it has a lower difference in concentration between the alpha and beta phases than vanadium, which in turn is related exponentially to the growth rate of the particle by the $\lambda$ term in Eqs. [5] and [6].

\section{B. Lamellar Precipitate Dissolution}

The experimental data taken from the initial lamellar structures present within the microstructure are as follows: (i) aspect ratio: 7.0, (ii) lamellae thickness: $3.0 \mu \mathrm{m}$, (iii) alpha lamellar phase fraction: 0.95, 


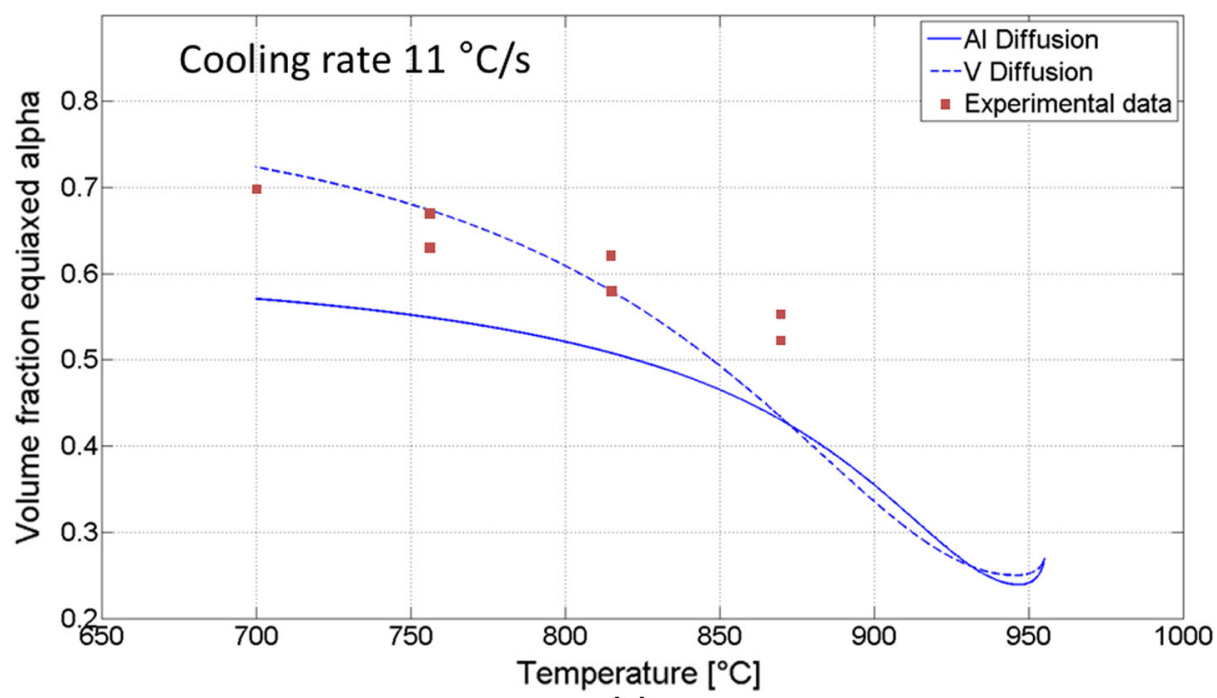

(a)

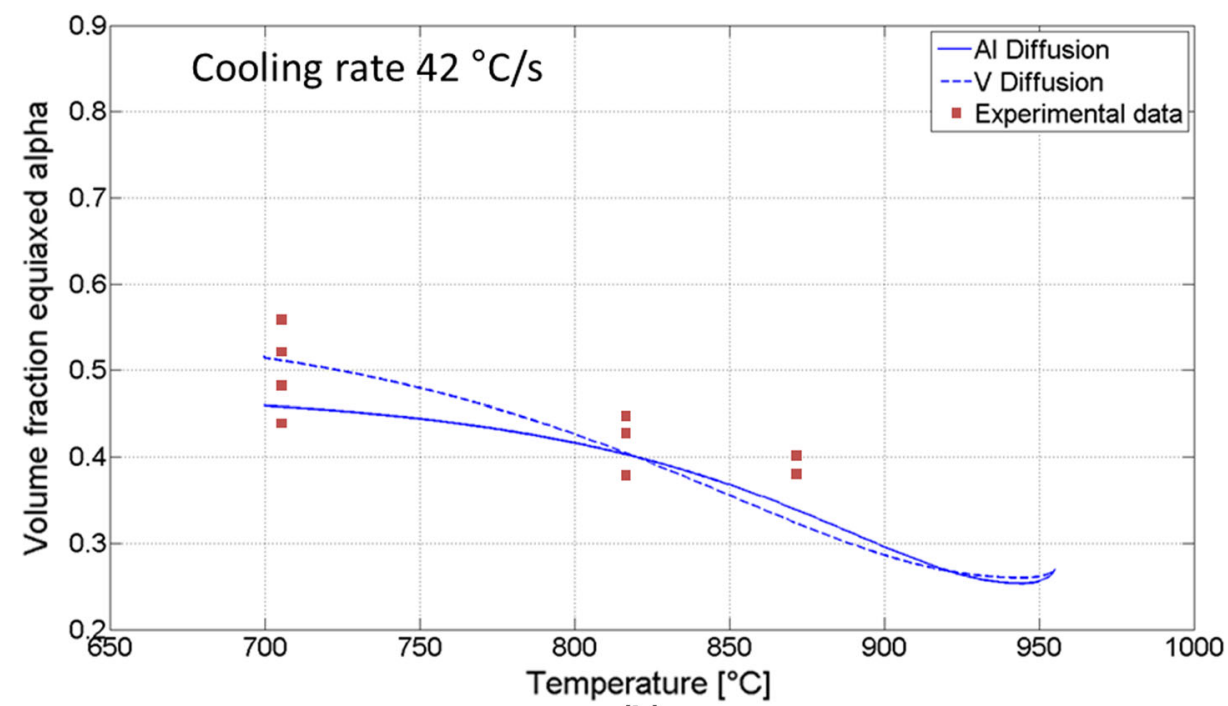

(b)

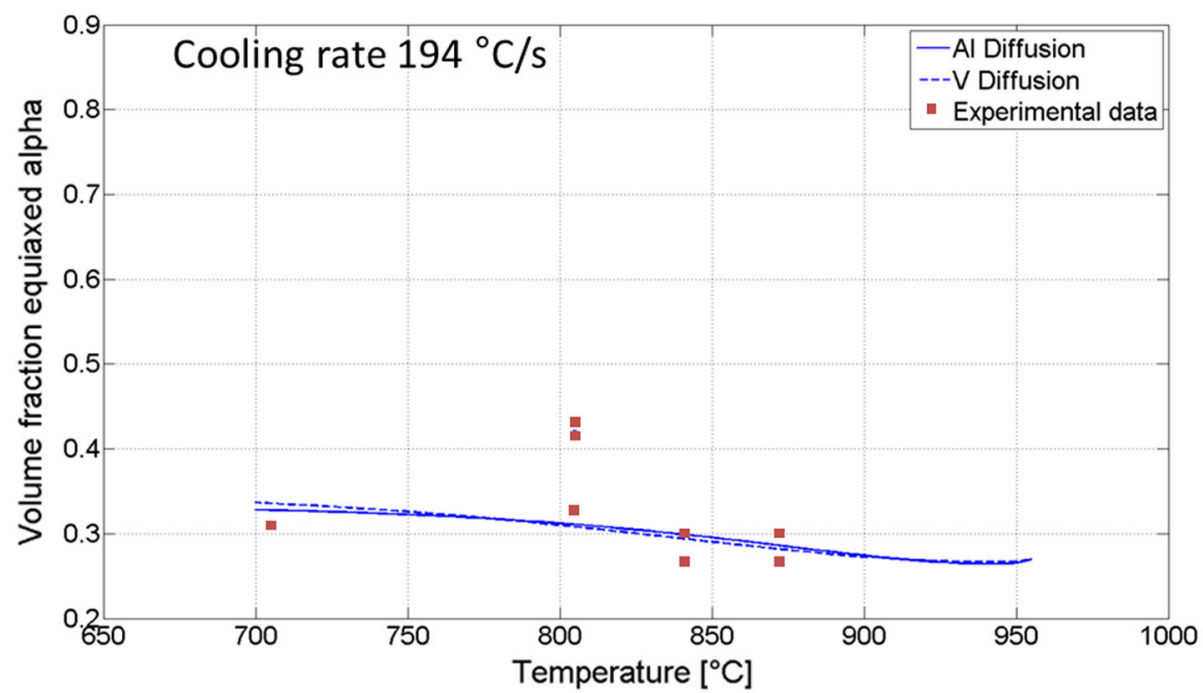

(c)

Fig. 8- Comparison of numerical (Al vs $\mathrm{V}$ diffusing elements) and experimental data ${ }^{[14]}$ for a heat treatments starting from $955{ }^{\circ} \mathrm{C}$ with cooling rates: (a) $11{ }^{\circ} \mathrm{C} / \mathrm{min},\left(\right.$ b) $42{ }^{\circ} \mathrm{C} / \mathrm{min},(c) 194{ }^{\circ} \mathrm{C} / \mathrm{min}$. 


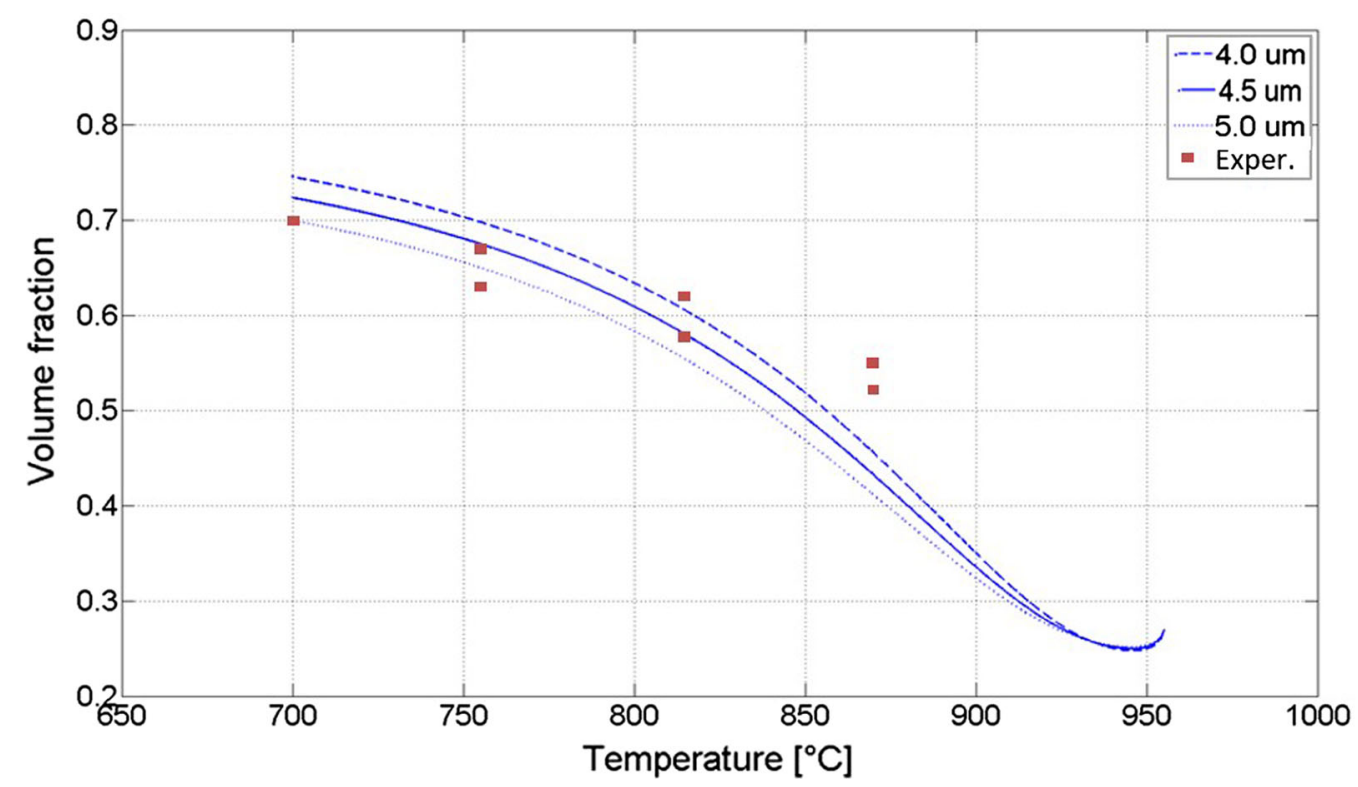

Fig. 9-Sensitivity of the different growth kinetics to the initial spherical particle size. Soaking temperature $955{ }^{\circ} \mathrm{C}$ and then cooling at $11{ }^{\circ} \mathrm{C} /$ min (Vanadium considered as diffusing element).

(iv) mean vanadium composition in the lamellar microstructure: $2.47 \mathrm{pct}$, (v) mean aluminum composition in the lamellar microstructure: 5.495 pct, and (vi) overall vanadium concentration in the material: 4.0479 pct. Since the model to describe the lamellar microstructure evolution showed very low sensitivity to small variations of the lamellae aspect ratio, a value of 7 was assumed to be constant for all the thermal treatments tested.

Comparisons of the numerical model predictions considering vanadium as diffusing element for lamellae thickness and the lamellae volume fraction against the experimental measurements carried out at heating rates of 5, 50, and $500{ }^{\circ} \mathrm{C} / \mathrm{s}$ are shown in Figures 10 and 11 . For temperatures close to the complete dissolution of lamellae, and for fast heating rates, the model predicts a gradual reduction of both the alpha lamellae thickness and phase fraction until a critical temperature, whereby the predicted value falls sharply to zero. This happens because of the low supersaturation at this stage of the transformation, which slows down shrinkage rate, resulting in dissolution being delayed to higher temperatures for very fast heating rates.

Thus, a complete mathematical framework has been presented for the prediction of both spherical and lamellar particle growth and shrinkage, suitable for detailed microstructural modeling of titanium during a range of heating rate processes. These models could potentially be embedded as sub-routines or sub-models within thermal-mechanical process modeling codes to allow for detailed titanium alloy microstructure predictions.

\section{PREDICTIONS FOR THE $\beta$-TRANSUS TEMPERATURE}

The diffusion process at fast heating rates does not have time to completely dissolve the alpha phase, and thus localized segregation is still visible by SEM. The switch in crystallographic structure from HCP to BCC will occur when the local temperature passes the betatransus temperature for the heating rate considered. As such, the dissolution model must be integrated with an experimental equation to predict the beta-transus temperature as a function of the temperature rate. To describe the change in crystallographic structure for fast heating rates, the approach presented in Reference 30 based on isochronal conditions applied to the JMA Eq. [31] has been used, giving Eq. [33]:

$$
\begin{gathered}
f=1-e^{-\eta^{n}} \\
\eta=k t=k_{0} t e^{-\frac{E}{\Upsilon T}} \\
\ln \frac{T_{\beta \phi}^{2}}{\phi}=\ln \frac{E}{\Upsilon k_{0}}+\frac{E}{\Upsilon T_{\beta \phi}}+\frac{J}{n^{2}} \frac{\Upsilon T_{\beta \phi}^{2}}{E}
\end{gathered}
$$

with $k_{0}$ being a pre-exponential factor, $E$ the activation energy of the phase transformation considered, $\mathrm{Y}$ the gas constant, $T$ temperature (in Kelvin), $\phi$ the heating rate, $J$ a constant, $n$ the exponential factor, and $T_{\beta \phi}$ the beta-transus temperature at a specific heating rate $\phi$. Thus, it is possible to predict the beta-transus 


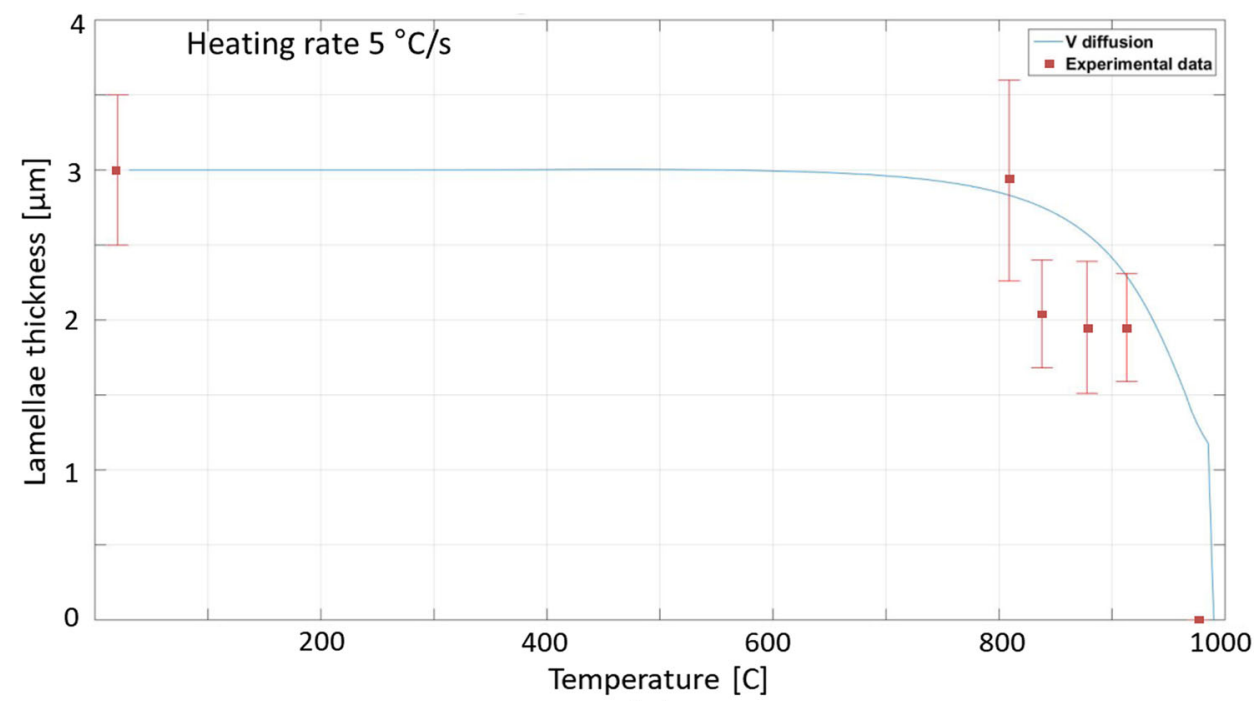

(a)

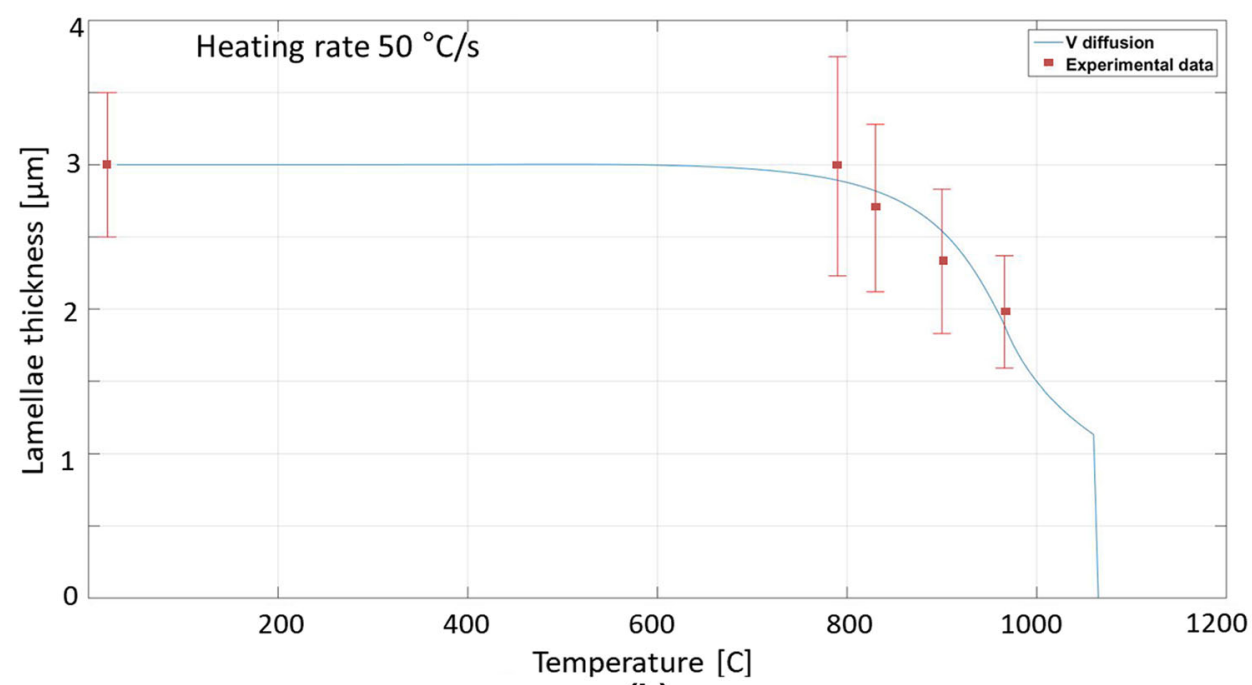

(b)

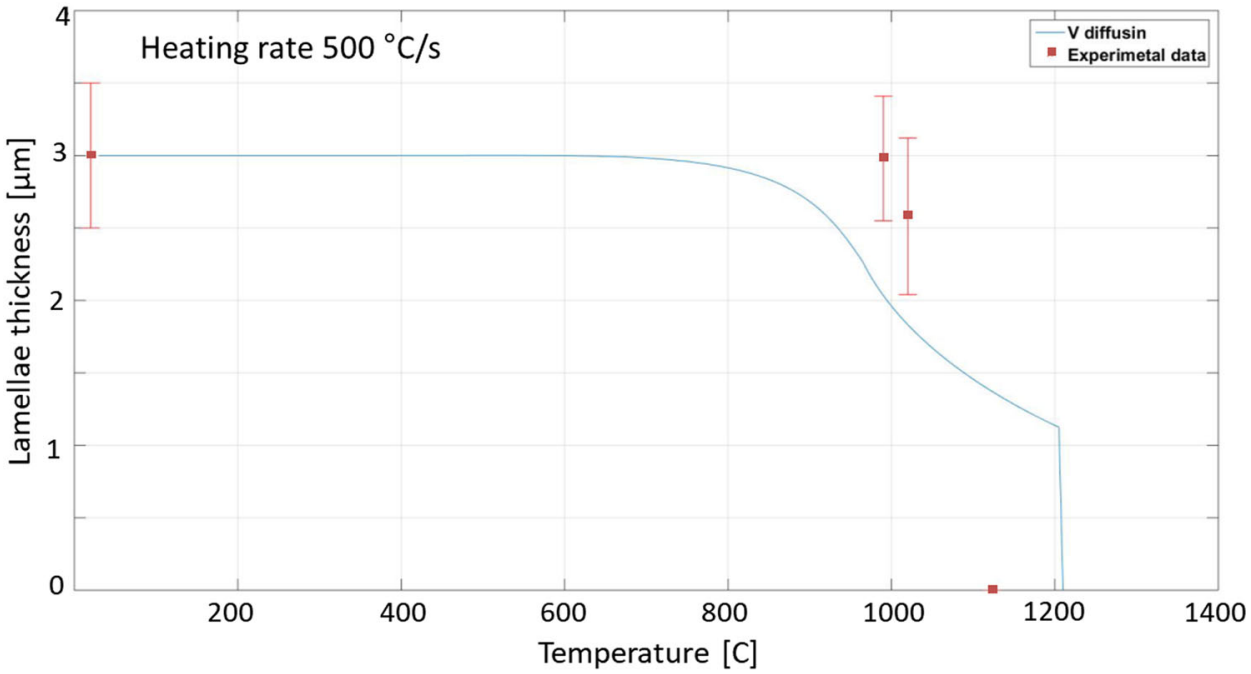

(c)

Fig. 10 - Comparison of lamellar thickness predicted by numerical model (Vanadium as diffusing element) and the experimental measurements, at heating rates of $(a) 5{ }^{\circ} \mathrm{C} / \mathrm{s},(b) 50^{\circ} \mathrm{C} / \mathrm{s},(c) 500^{\circ} \mathrm{C} / \mathrm{s}$. 


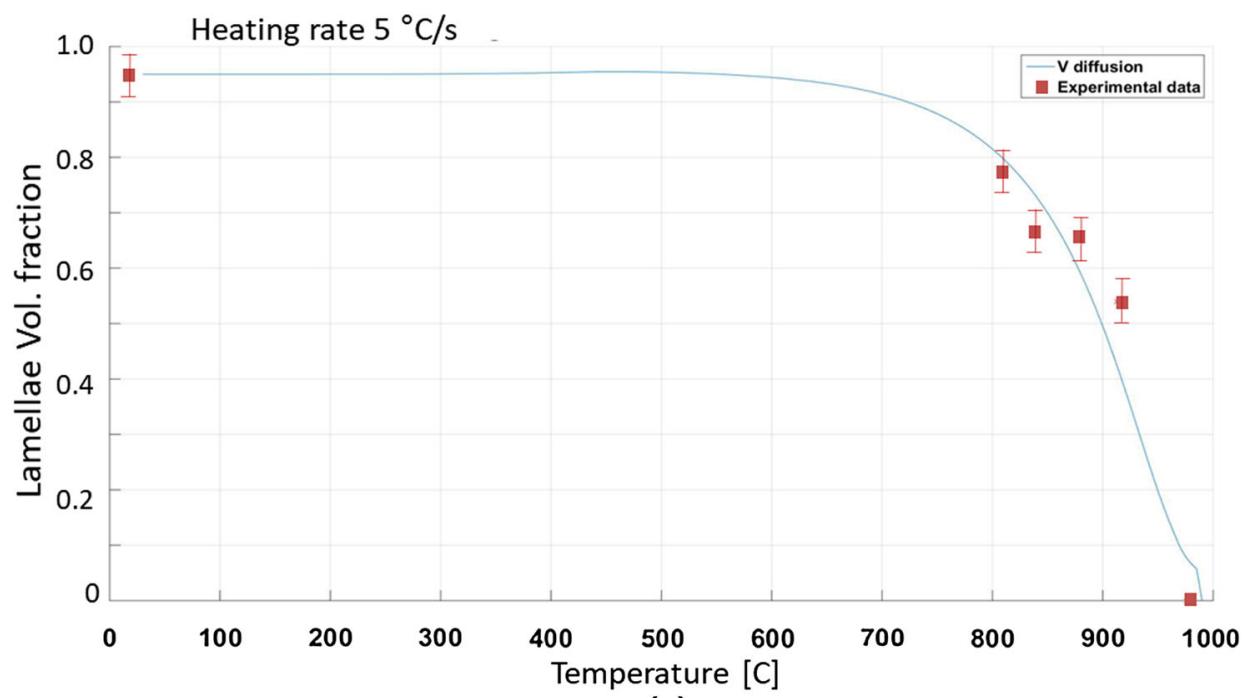

(a)

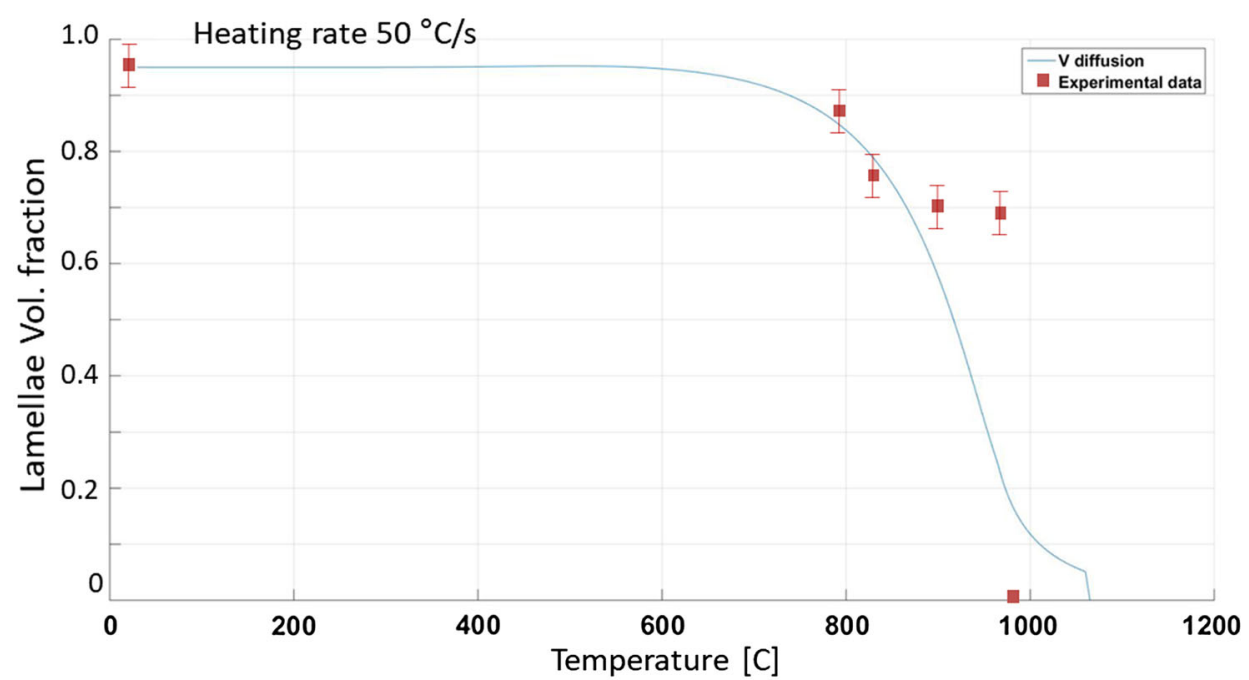

(b)

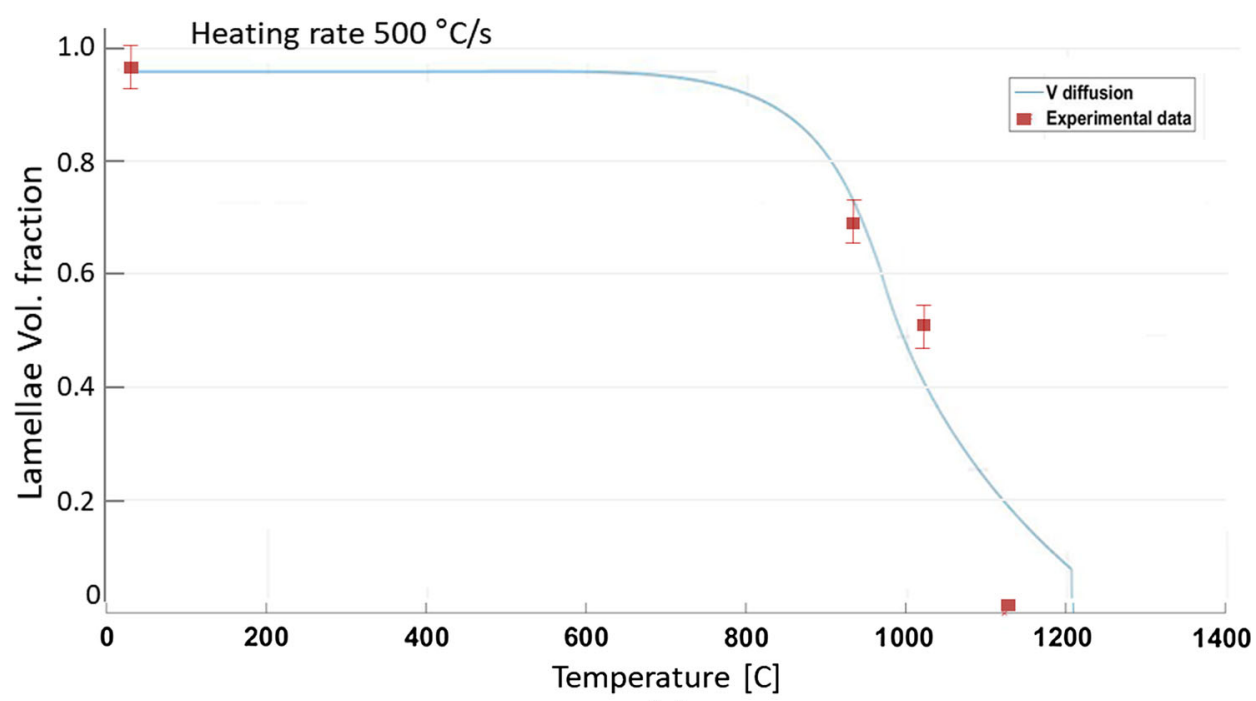

(c)

Fig. 11-Comparison of alpha lamellar volume fraction predicted by numerical model (Vanadium as diffusing element) and experimental measurements, at heating rates of $(a) 5{ }^{\circ} \mathrm{C} / \mathrm{s},\left(\right.$ b) $50{ }^{\circ} \mathrm{C} / \mathrm{s},(c) 500{ }^{\circ} \mathrm{C} / \mathrm{s}$. 


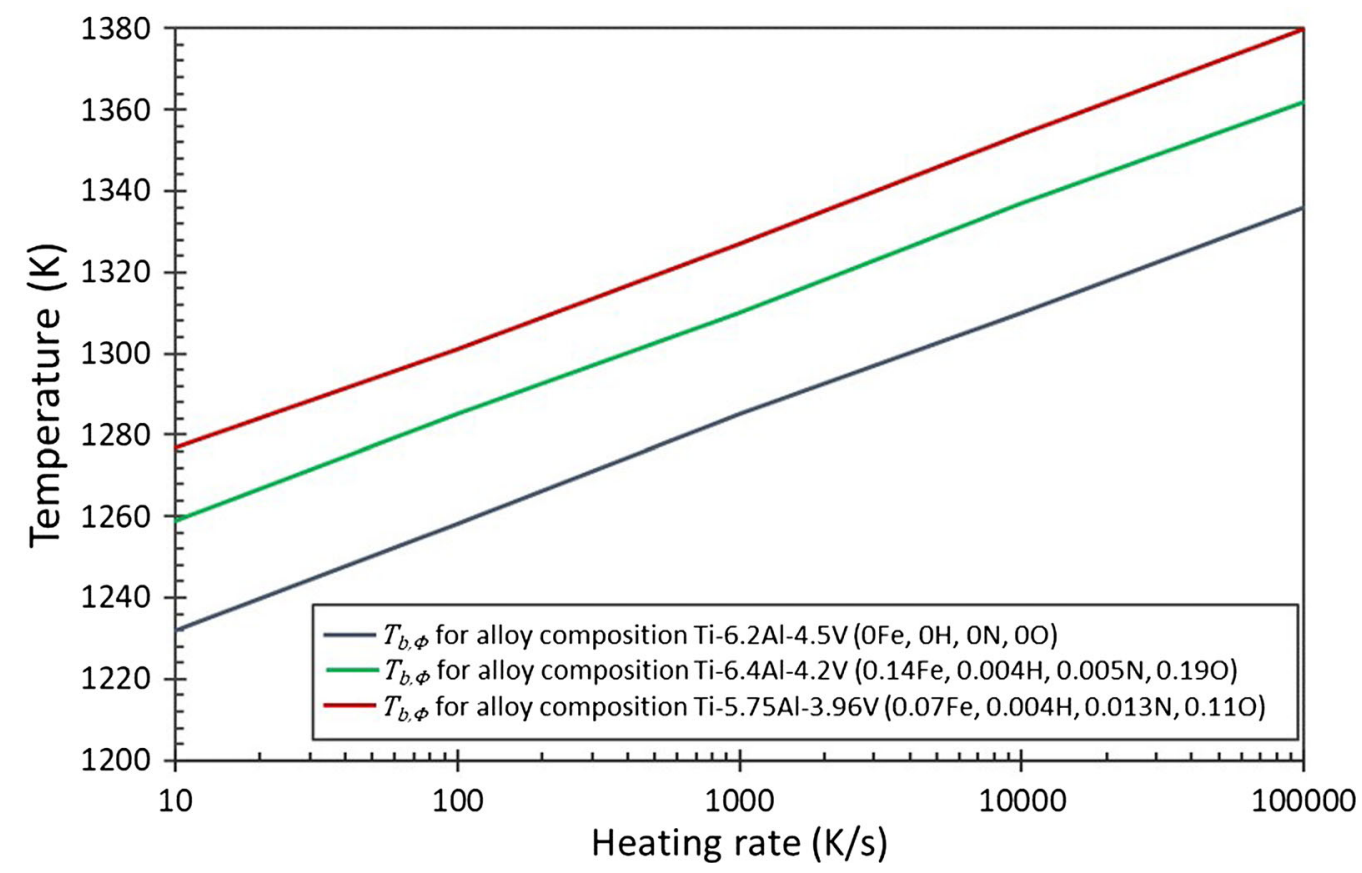

Fig. 12-Beta-transus temperature variation predictions for the proposed model, for small differences in composition for nominal Ti-6Al-4V.

Table II. Parameters Used for Eq. [33]

\begin{tabular}{lccc}
\hline$E(\mathrm{~J} / \mathrm{mol})$ & $K_{0}(1 / \mathrm{s})$ & $J$ & $n$ \\
\hline 494,830 & $488,160,301$ & -0.466 & 0.633 \\
\hline
\end{tabular}

temperature at a desired heating rate. The JMA equation has been utilized for alpha-phase titanium modeling previously, ${ }^{[31]}$ with Widmanstatten, martensite, and grain boundary alpha being considered to be separate phases, controlled within the model by state variables. The phase transformations were modeled based on a diffusional theory described by the JohnsonMehl-Avrami-Kolmogorov formulation, a parabolic rate law for $\alpha$ dissolution on heating, as well as diffusionless transformation for the martensite formation.

To fully integrate the heating rate-dependent betatransus calculation, one must apply an empirical relationship with the alpha- or beta-stabilizer elements in a Ti-6Al-4V alloy. The JMatPro materials database, a thermodynamic software based upon the CALPHAD method and employing fundamental physical principles, ${ }^{[32]}$ was consulted for different chemical compositions of the Ti-6Al-4V alloy to quantify their effect on the beta-transus temperature. From Eqs. [34] and [35], the equivalent aluminum and vanadium content for a specific alloy are calculated, in weight percent, and their combined effect on the beta-transus temperature is subsequently calculated (Eq. [36]). It is therefore possible to predict the beta-transus temperature for the desired chemical composition.

$$
\begin{gathered}
A l_{\text {eq new alloy }}=A l+10 O+40 N \\
V_{\text {eq new alloy }}=V+66 H+1.25 F e \\
\Delta T_{\beta \phi}=20\left(A l_{\text {eq ref.alloy }}-A l_{\text {eq new alloy }}\right) \\
-20\left(V_{\text {eq ref.alloy }}-V_{\text {eq new alloy }}\right)
\end{gathered}
$$

Figure 12 illustrates the model predictions for changes in $T_{\beta \phi}$ with differing cooling rates. The data for the Ti-6.2Al-4.5V composition were taken from the literature $^{[33]}$ for the slower heating rates up to $100 \mathrm{~K} / \mathrm{s}$, and applying Eq. [33] for faster heating rates, using parameters as in Table II. The $T_{\beta \phi}$ predictions for the other two hypothetical small compositional variations of alloy Ti-6Al-4V (including trace elements Fe, N, H, and O) were made using Eqs. [33] through [36].

\section{CONCLUSIONS}

A diffusion-based mathematical framework has been developed and coded to describe the growth and shrinkage of alpha equiaxed and lamellar microstructures for Ti-6Al-4V in the $\alpha+\beta$ field. The validation of the model has been carried out using data from previous literature for the equiaxed microstructure, and by experiments for the lamellar microstructure. The following conclusions are drawn:

- For equiaxed grains, the model predicts the phase fraction evolution during cooling reasonably when considering vanadium as the single diffusing element, 
and better than with aluminum as the diffusing element. For lower heating rates, this difference is exacerbated, whereas at higher cooling rates both vanadium and aluminum diffusion results converge. The predictions are relatively insensitive to small measurement errors of initial particle size.

- For lamellar structures, the model predicts the correct trends for lamellae thickness and volume fraction values, with some error in the thickness calculations being more noticeable for the fastest heating rate. The latter could be due to the high internal energy of the material, allowing a switch to the more stable BCC crystallographic structure even though the dissolution of the alpha phase is incomplete.

- In order to determine the beta-transus as a function of the heating rate, a JMA approach was adopted and applied to the diffusion-based model to establish when a complete transition from alpha to beta phase was obtained; this was independent of the state of the alpha-phase dissolution.

\section{OPEN ACCESS}

This article is distributed under the terms of the Creative Commons Attribution 4.0 International License (http://creativecommons.org/licenses/by/4.0/), which permits unrestricted use, distribution, and reproduction in any medium, provided you give appropriate credit to the original author(s) and the source, provide a link to the Creative Commons license, and indicate if changes were made.

\section{REFERENCES}

1. R.R. Boyer: Mater. Sci. Eng. A, 1996, vol. 213, pp. 103-14.

2. P.F. Mendez and T.W. Eagar: Adv. Mater. Process, 2001, vol. 159, pp. 39-43.

3. M. Avrami: J. Chem. Phys., 1939, vol. 7 (12), pp. 1103-12.

4. M. Avrami: J. Chem. Phys., 1940, vol. 8 (2), pp. 212-24.

5. M. Avrami: J. Chem. Phys., 1941, vol. 9 (2), pp. 177-84.

6. R. Ding, Z.X. Guo, and A. Wilson: Mater. Sci. Eng. A, 2002, vol. 327 (2), pp. 233-45.
7. F.J. Gil, J.M. Manero, M.P. Ginebra, and J.A. Planell: Mater. Des., 2003, vol. 349, pp. 150-55.

8. J. Tiley, T. Searles, E. Lee, R. Banerjee, J. Russ, and H. Fraser: Mater. Sci. Eng. A, 2004, vol. 372 (1-2), pp. 191-98.

9. S.L. Semiatin, T.M. Lehner, J.D. Miller, R.D. Doherty, and D.U. Furrer: Metall. Mater. Trans. A, 2007, vol. 38A (4), pp. 910-21.

10. R.P. Turner, B. Perumal, Y. Lu, R.M. Ward, H.C. Basoalto, and J.W. Brooks: Metall. Mater. Trans. B, 2019, vol. 50B, pp. 1000-08.

11. H.B. Aaron: J. Appl. Phys., 1970, vol. 41 (11), p. 4404.

12. H.R. Shercliff and O. Grong: Prog. Mater. Sci., 2002, vol. 47, pp. 163-282.

13. F.S. Ham: J. Phys. Chem. Solids, 1958, vol. 6, pp. 335-51.

14. S.L. Semiatin, S.L. Knisley, P.N. Fagin, F. Zhang, and D.R. Barker: Metall. Mater. Trans. A, 2003, vol. 34A, pp. 2377-2386.

15. S. Zhu, H. Yang, L.G. Guo, and X.G. Fan: Mater. Charact., 2012, vol. 70, pp. 101-10.

16. Q. Chen, N. Ma, K. Wu, and Y. Wang: Scripta Mater., 2004, vol. 50 (4), pp. 471-476.

17. H.B. Aaron and G.R. Kotler: Metall. Trans., 1971, vol. 2, pp. $393-$ 408.

18. D.A. Porter and K.E. Easterling: Phase Transformations in Metals and Alloys, Chapman \& Hall, London, 1992.

19. Y. Mishin and C. Herzig: Acta Mater., 2000, vol. 48 (3), pp. 589 623

20. Y. Wang, N. Ma, Q. Chen, F. Zhang, S. Chen, and Y.A. Chang: JOM, 2005, vol. 57, pp. 32-39.

21. M.J. Whelan: Met. Sci. J., 1969, vol. 3 (4), pp. 95-97.

22. G. Horvay and J.W. Cahn: Acta Metall., 1961, vol. 9, pp. 695-705.

23. M. Ferrante and R.D. Doherty: Acta Metall., 1979, vol. 27 (10), pp. $1603-14$

24. A. Rostamian and A. Jacot: Intermetallics, 2008, vol. 16 (10), pp. $1227-36$.

25. H. Wang, N. Warnken, and R.C. Reed: Mater. Sci. Eng. A, 2010, vol. $528(2)$, pp. $622-630$.

26. U.R. Kattner: $J O M$, 1997, vol. 49 (12), pp. 14-19.

27. A.T. Dinsdale: CALPHAD, 1991, vol. 15 (4), pp. 317-425.

28. I. Katzarov, S. Malinov, and W. Sha: Metall. Mater. Trans. A, 2002, vol. 3A (4), pp. 1027-40.

29. T. Searles, J. Tiley, A. Tanner, R. Williams, B. Rollins, E. Lee, S. Kar, R. Banerjee, and H.L. Fraser: Meas. Sci. Technol., 2005, vol. 16 (1), pp. $60-69$.

30. E.J. Mittemeijer, A. van Gent, and P.J. van der Schaaf: Metall. Mater. Trans. A, 1986, vol. 17, pp. 1441-1445.

31. C. CharlesMurgau, R. Pederson, and L.-E. Lindgren: Model. Simul. Mater. Sci. Eng., 2012, vol. 20, p. 055006.

32. N. Saunders, U.K.Z. Guo, X. Li, A.P. Miodownik, and J.-P. Schillé: $J O M, 2003$, vol. 55, p. 60.

33. W. Szkliniarz and G. Smotka: J. Mater. Process. Tech., 1995, vol. 53 (3), pp. 413-22.

Publisher's Note Springer Nature remains neutral with regard to jurisdictional claims in published maps and institutional affiliations. 